\title{
Effect of Clausena excavata Burm. f. (Rutaceae) leaf extract on wound healing and antioxidant activity in rats
}

\author{
This article was published in the following Dove Press journal: \\ Drug Design, Development and Therapy \\ 13 July 2015 \\ Number of times this article has been viewed
}

\author{
Shaymaa Fadhel Abbas \\ Albaayit ${ }^{1,2}$ \\ Yusuf $\mathrm{Abba}^{3}$ \\ Abdullah Rasedee ${ }^{3}$ \\ Noorlidah Abdullah' \\ 'Institute of Biological Sciences, \\ Faculty of Science, University \\ of Malaya, Kuala Lumpur, Malaysia; \\ ${ }^{2}$ Department of Biology, College \\ of Science, University of Baghdad, \\ Baghdad, Iraq; ${ }^{3}$ Department of \\ Pathology and Microbiology, Faculty \\ of Veterinary Medicine, Universiti \\ Putra Malaysia, Serdang, Selangor, \\ Malaysia
}

\begin{abstract}
Clausena excavata is a well-known plant used in folkloric medicine for the treatment of different ailments. This study aimed to determine the in vitro cytoxicity of its leaf solvent extracts as well as the in vivo wound healing and antioxidant activities of the methanolic extracts of C. excavata (MECE). HaCaT (keratocyte) and Vero cell lines were used for evaluation of the in vitro cytotoxic effects, while the in vivo wound healing and antioxidant activities were determined in skin wounds inflicted on rats. Twenty adult male Sprague-Dawley rats were divided into five groups of four animals each. Approximately $3.14 \mathrm{~cm}^{2}$ excisional wound was inflicted on the nape of each rat following anesthesia. The treatment groups received topical application of MECE at $50 \mathrm{mg} / \mathrm{mL}$ (MECE-LD [low dose]), $100 \mathrm{mg} / \mathrm{mL}$ (MECE-MD [medium dose]), and $200 \mathrm{mg} / \mathrm{mL}$ (MECE-HD [high dose]), while the negative control group was treated with gum acacia in normal saline and the positive control group with intrasite gel. Wound contraction was evaluated on days 5,10 , and 15 after wound infliction, and tissue from wound area was collected at day 15 postwound infliction for antioxidant enzyme evaluation and histopathological analyses. Generally, Vero cells were more resistant to the cytotoxic effects of the solvent extracts as compared with $\mathrm{HaCaT}$ cells. Chloroform $(\mathrm{CH})$ and ethyl acetate (EA) extracts of $C$. excavata were toxic to HaCaT cells at 200 and $400 \mu \mathrm{g} / \mathrm{mL}$, but the same concentrations showed higher $(P<0.05)$ viability in Vero cells. There was significantly $(P<0.01)$ greater wound contraction at days 10 and 15 postwound infliction in all the treatment groups than in the control groups. Histopathologically, the MECE-HD-treated wound showed significantly $(P<0.05)$ lesser inflammatory cell proliferation, degeneration, and distribution of granulation tissue than other groups. Similarly, the degree of collagen maturation, angiogenesis, and collagen distribution were significantly $(P<0.05)$ lower in MECE-HD than in other groups. The MECE-HD, MECE-MD, and intrasite treatment groups showed a significantly $(P<0.05)$ higher number of VEGF-positive and TGF- $\beta 1$-positive cells in the skin wound than the control groups. The activities of superoxide dismutase and catalase were significantly $(P<0.01)$ higher in the MECE-HD and intrasite treatment groups than in the other groups. Lipid peroxidase activity of the treated groups was significantly $(P<0.01)$ lower than that in the control group. The study showed that MECE is a potent wound healing agent through anti-inflammatory and antioxidant effects that enhanced the rate of wound contraction, re-epithelialization, and collagen deposition. The effect of MECE is suggested to be due to its high polyphenolic compound content.
\end{abstract}

Keywords: Clausena excavata, cytotoxicity, wound healing, antioxidant, histopathology, VEGF, TGF- $\beta 1$

\section{Introduction}

Clausena excavata Burm. f. is one of the potherb species with high antioxidant properties. Its leaves and stem are used in folk medicine for treatment disorders such 
as colic, cough, headache, rhinitis, sores, wounds, fever, and detoxification. This plant has been reported to possess various biological properties including anti-inflammatory, antimicrobial, antinociceptive and immunomodulatory, antifungal, antioxidant, and analgesic properties. ${ }^{1-5}$ The acetone extract of its leaves has been shown to contain several furanocoumarins with in vitro antiproliferative activities on cancer cells. ${ }^{5}$

Wound healing is a complex process involving both biochemical and physiological changes. A wound provides an environment for the growth of microorganisms, and thus an infected wound shows delayed or prolonged healing time. ${ }^{6}$

During the inflammation phase, various inflammatory cells like neutrophils, macrophages, fibroblasts, and endothelial cells produce a sudden burst of reactive oxygen species (ROS) in the site of the wound, providing signaling and defense against invading microorganisms. ROS, which include hydroxyl radical, superoxide anion, hydrogen peroxide, and singlet oxygen, have destructive action on both DNA and proteins. Overproduction of ROS may also hinder the rate of wound healing by causing damage to surrounding cells. Thus, as expected, plants possessing antioxidant properties can prevent oxidative damage to cells induced by wound injury, thereby promoting healing. ${ }^{7,8}$

One of the many mechanisms of wound healing is the promotion of angiogenesis in the injured tissue. Vascular endothelial growth factor (VEGF) and transforming growth factor $\beta 1$ (TGF- $\beta 1$ ) are among the effectors of angiogenesis, granulation tissue formation, collagen synthesis, and extracellular matrix deposition. ${ }^{9,10}$ Increased expressions of these factors are associated with acceleration of wound healing. ${ }^{11}$

C. excavata possesses strong antioxidant properties and is a rich source of polyphenol compounds such as coumarins, carbazole alkaloid, and flavonoid glycosides. ${ }^{4,5,12,13}$ However, there is no clear evidence that $C$. excavata, with its potent antioxidant activity, can enhance wound healing in the animal model. This study was thus undertaken to determine the in vitro effect of $C$. excavata extracts on HaCaT (keratinocyte) and Vero cells, and the in vivo effect on experimentally induced skin wound in rats.

\section{Materials and methods}

\section{Collection, identification, processing, and extraction of plant material}

C. excavata leaves were collected, identified by Dr Shamsul Khamis (Resident Botanist) at the Biodiversity unit, Institute of Bioscience, Universiti Putra Malaysia, processed, and extracted as previously described by Albaayit et al. ${ }^{14}$

Briefly, extraction was done successively at room temperature using petroleum ether (PT) followed by chloroform
$(\mathrm{CH})$, ethyl acetate (EA), and methanol (MOH). The extraction at a 1:5 dried plant weight to volume ratio began with PT for 3 days. The filtrate was collected, and the residues were subjected to further extraction with $\mathrm{CH}, \mathrm{EA}$, and $\mathrm{MOH}$, respectively, and the filtrates were collected after each solvent extraction. All filtrates were evaporated until dryness using a rotary evaporator at $45^{\circ} \mathrm{C}-50^{\circ} \mathrm{C}$ to obtain crude extracts and stored at $4^{\circ} \mathrm{C}$ until use. Among the extracts, methanolic extract Clausena excavata (MECE) exhibited the most potent antioxidant activity, and hence it was selected for wound healing potential in this study.

\section{In vitro screening of different solvent crude extracts}

\section{Cell maintenance}

The HaCaT and Vero cell lines (American Type Culture Collection [ATCC], Manassas, VA, USA) were cultured in $75 \mathrm{~cm}^{3}$ T-flasks using RPMI and DMEM media, respectively, fortified with $10 \%$ fetal bovine serum, and incubated at $37^{\circ} \mathrm{C}$ in a $5 \% \mathrm{CO}_{2}$ humidified incubator. Cells reaching $80 \%$ confluency were detached using Trypsin-EDTA (Thermo Fisher Scientific, Waltham, MA, USA), centrifuged at $1,710 \times g$, and counted using trypan blue exclusion assay.

\section{Evaluation of crude extract fractions on cell viability} using (3-(4,5-dimethylthiazol-2-yl)-2,5-diphenyltetrazolium bromide [MTT]) colorimetric assay

The MTT assay is one of the most commonly used colorimetric indices to determine cell viability/cytotoxicity. ${ }^{15}$ The HaCaT and Vero cells were seeded at a density of $6.0 \times 10^{3}$ cells/well in a 96-well plate. After incubation for 24 hours, the cells were washed with phosphate buffered saline (PBS). The drug was prepared using corresponding growth media for each cell line. The vehicle for initial stock of drug was $0.1 \%$ dimethyl sulfoxide (DMSO). Approximately 12.5, 25, 50, 100, 200, and $400 \mu \mathrm{g} / \mathrm{mL}$ of the methanolic $\mathrm{MOH}, \mathrm{EA}, \mathrm{CH}$, and PT crude extracts were added to the cells and incubated at $37^{\circ} \mathrm{C}$ and $5 \% \mathrm{CO}_{2}$ for 24 hours. Twenty microliters of MTT reagent was then added to each well and incubated for 3 hours. The purple formazan formed was solubilized with $150 \mu \mathrm{L}$ of DMSO in the dark at room temperature for approximately 30 minutes. The absorbance was recorded at $570 \mathrm{~nm}$, with reference at $630 \mathrm{~nm}$, in a microplate reader (Tecan, Salzburg, Austria). Each experiment was repeated three times with triplicate wells for each concentration.

\section{Experimental animal}

Twenty adult male Sprague-Dawley rats (200-250 g) were used in the study. The rats were acclimatized for 2 weeks 
in a well-ventilated room, and standard pellet feed and tap water were provided ad libitum throughout the experimentation period. The project proposal was approved by the Institutional Animal Care and Use Committee, University of Malaya (ISB/22/007/2013/1111/SFA).

\section{Wound infliction}

The rats were divided into five groups of four animals each, and all animals were anesthetized with an intramuscular injection of ketamine/xylazine at the ratio of $3: 1(100 \mathrm{mg} / \mathrm{mL}$ and $30 \mathrm{mg} / \mathrm{mL}$, respectively), prior to infliction of skin wounds. Skin from the dorsal nape of the neck was shaved with an electrical clipper, disinfected with 70\% alcohol, and injected with $0.1 \mathrm{~mL}$ lignocaine hydrochloride $(2 \%$, $100 \mathrm{mg} / 5 \mathrm{~mL})$. A $2 \mathrm{~cm}$ diameter circular area $\left(-3.14 \mathrm{~cm}^{2}\right)$ of the skin was made using a circular stamp, and full thickness of the marked skin was then cut carefully by sterile scissors and forceps (Figure 1). Wound excision was done carefully to avoid muscle incision. Group 1 (negative control group) was treated with vehicle (gum acacia in normal saline $20 \mathrm{mg} / \mathrm{mL}$ ); Group 2 was treated with $0.2 \mathrm{~mL}$ intrasite gel (positive control group); Groups 3, 4, and 5 were treated with $0.2 \mathrm{~mL}$ C. excavata $\mathrm{MOH}$ extract (MECE) at concentrations of 50 (MECE-LD [low dose]), 100 (MECE-MD [medium dose]), and 200 (MECE-HD [high dose]) mg/mL. All treatments were by topical application twice daily for 14 days starting from day 0 of wound infliction.

\section{Wound contraction}

After the surgical process, the wound area was measured every 5 days for 15 days by placing transparent paper and defining the borders of the wound. The transparent paper was immediately traced out and placed on a $1 \mathrm{~mm}^{2}$ graph paper. The rate of change in wound contraction was expressed as a percentage of the initial wound size as given in the formula below. Differences in wound healing of the treated groups are derived by comparing with healed wound area of the control group on the respective days. ${ }^{16}$

$$
\begin{gathered}
\text { Wound } \\
\text { contraction }
\end{gathered}=\frac{\text { Original wound area }- \text { present wound area }}{\text { Total wound area }} \times 100
$$

\section{Histopathological examinations}

\section{H\&E- and Masson trichome-stained sections}

On day 15 of the experiment, skin specimens from all the rats were collected in $10 \%$ buffered formalin, processed, sectioned, and stained with hematoxylin and eosin (H\&E) and Masson's trichrome (MT). Six microscopic fields were examined from three slides per group at $400 \times$ magnification and the lesions scored based on a five-point scale: 0 - normal, $0 \%$; 1 - occasional evidence, $25 \% ; 2$ - light scattering, 30\%-50\%; 3 - abundant evidence, $55 \%-75 \%$; and 4 - confluent cell, $80 \%-100 \%$. The H\&E-stained sections were examined for epithelialization (based on complete or incomplete epithelial proliferation in the epidermal layer), degeneration (based on the distribution of epidermal cells showing vacuolation or vacuolar degeneration), granulation tissue (based on the distribution of necrotic and inflammatory cells in the microscopic fields), and leucocytic infiltration (based on the distribution of polymorphonuclear and mononuclear cells in the microscopic fields) under light microscopy (Olympus BX60; Olympus, Tokyo, Japan) and the images captured (Olympus XC10 camera, Olympus).

The MT sections were similarly evaluated for color intensity (based on a subjective assessment of blue color intensities: no coloration [0], low [1], dull [2], moderate [3], and bright colorations [4]); fibroblast distribution (based on the distribution of fibroblast cells in the microscopic
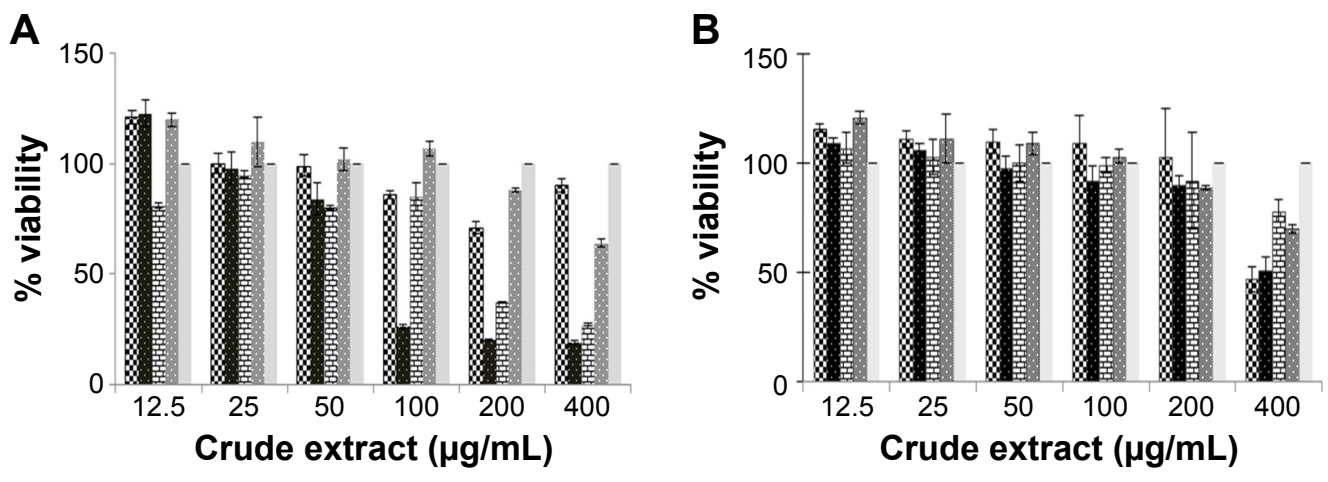

$$
\mathbf{M O H} \quad \text { EA } \quad \text { 吕 } \mathrm{CH} \text { Control }
$$

Figure I Cell viability evaluation following MTT assay on $\mathrm{HaCaT}(\mathbf{A})$ and Vero cells (B) treated with different crude extracts.

Abbreviations: $\mathrm{MOH}$, methanol; EA, ethyl acetate; $\mathrm{CH}$, chloroform; PT, petroleum ether; MTT, 3-(4,5-dimethylthiazol-2-yl)-2,5-diphenyltetrazolium bromide. 
field); collagen maturity (based on the level of maturation of collagen fibers: no collagen [0], semithin fibers [1], thin fibers [2], semithick fibers [3], thick fibers [4]); angiogenesis rate (based on the distribution of new blood capillaries in the microscopic field); and collagen distribution (based on the distribution of collagen fibers in the microscopic fields) using the five-point scale modified as previously described. ${ }^{9}$

\section{Staining for VEGF and TGF- $\beta$ I}

Tissue sections were routinely prepared as described earlier for histopathology. The tissue sections were deparaffinized and immersed in graded concentrations of alcohol $(100 \%$, $80 \%, 70 \%$, and $50 \%$ ) for 5 minutes before being hydrated in PBS twice for 5 minutes. The sections were boiled in $10 \mathrm{mM}$ Tris buffer ( $\mathrm{pH}$ 9.0) for 15 minutes to retrieve the antigen, and the slides were cooled, blocked by endogenous peroxide, and incubated for 10 minutes with $3 \% \mathrm{H}_{2} \mathrm{O}_{2}$. The slides were then washed twice in PBS and incubated with polyclonal primary antibodies (anti-VEGF or anti-TGF- $\beta 1$ ), Tween-20 rabbit polyclonal anti-VEGF or anti-TGF- $\beta 1$ antibody (Abcam, Cambridge, UK) at a dilution of 1:500 and 1:100, respectively, and the tissue was incubated in a humidified chamber at $4^{\circ} \mathrm{C}$ for 1 hour (VEGF) or 18 hours (TGF- $\beta 1$ ) overnight. The tissues were then stained with 3,3'diaminobenzidine tetrahydrochloride (DAB) and substrate (Dako, Carpintaria, CA, USA) for 5 minutes. All washings were done with $0.1 \%$ Tween-20 in PBS, except for washings after rehydration and after chromogen incubation (DAB), in which PBS without Tween-20 was used. The slides were counterstained with hematoxylin, and subsequently dehydrated in increasing concentrations of alcohol $(50 \%, 70 \%$, $80 \%$, and $100 \%$ ) before being cleared in xylene. Tissue sections were air-dried and mounted onto slides for examination under light microscopy. Stained sections were evaluated for VEGF-positive cells in six fields each from three cut sections per group at $400 \times$ magnification. Positive cells stained light to dark brown were counted in each microscopic field. The extracellular matrix (ECM) distribution was evaluated from TGF- $\beta 1$-stained sections by using a four-point scale: 0 - no ECM, 0\%; 1 - little ECM, 25\%-40\%; 2 - moderate ECM, $50 \%-65 \%$; and 3 - confluent ECM, 70\%-100\%, modified as previously described. ${ }^{9}$

\section{Antioxidant activity}

Tissues samples were collected from all the animals at day 15 post-wound infliction for the determination of tissue superoxide dismutase (SOD), catalase (CAT), glutathione peroxidase (GPx), and lipid peroxidase activities.

\section{Superoxide dismutase activity}

The tissues were homogenized (Omni TH; Omni, Kennesaw, GA, USA) in $20 \mathrm{mM}$ HEPES buffer (1 mM EGTA, $210 \mathrm{mM}$ mannitol, and $70 \mathrm{mM}$ sucrose/g tissue), $\mathrm{pH}$ 7.2. The homogenate was then centrifuged at $1,500 \times g$ for 5 minutes at $4^{\circ} \mathrm{C}$, and the supernatant assayed for SOD activity using the Cayman assay kit (Cayman Chemical, Ann Arbor, MI, USA; www.caymanchem.com/pdfs/706002.pdf).

\section{Catalase activity}

Tissue samples were homogenized (Omni TH, Omni) in cold potassium phosphate buffer, $\mathrm{pH} 7.0$, containing $1 \mathrm{mM}$ EDTA. The mixture was then centrifuged at $10,000 \times g$ for 15 minutes at $4^{\circ} \mathrm{C}$, and the supernatant assayed for CAT activity using the Cayman assay kit (Cayman Chemical; www.caymanchem.com/pdfs/707002.pdf).

\section{Glutathione peroxidase activity}

Tissue samples were homogenized (Omni TH, Omni) in $50 \mathrm{mM}$ Tris- $\mathrm{HCl}, \mathrm{pH} 7.5,5 \mathrm{mM}$ EDTA, and $1 \mathrm{mM}$ dithiothreitol. The homogenate was then centrifuged at $10,000 \times g$ for 15 minutes at $4^{\circ} \mathrm{C}$. The supernatant was assayed for GPx activity using the Cayman assay kit (Cayman Chemical; www.caymanchem.com/pdfs/703102.pdf).

\section{Lipid peroxidation activity}

The lipid peroxidation (LPO) assays (Cayman Chemical) were carried out according to manufacturer's instructions. Tissue samples were homogenized (Omni TH, Omni) in PBS, $\mathrm{CH}$, and extraction buffer provided with the kit to extract lipid hydroperoxides. Real-time chromogenic reaction was allowed to occur for 5 minutes. The absorbance was read at $500 \mathrm{~nm}$ (www.caymanchem.com/pdfs/705003.pdf).

\section{Statistical analysis}

Data obtained from the experiments were expressed as mean \pm SE (standard error of mean), and subjected to one-way analysis of variance using SPSS (Version 19.0; IBM Corporation, Armonk, NY, USA) with significance at $P<0.001$ and $P<0.05$. The analyzed data were then presented in tables and bar graphs as shown.

\section{Results}

\section{Cytotoxicity assay}

The MTT cytotoxicity assay showed that $\mathrm{MOH}$ and PT extracts were less toxic to $\mathrm{HaCaT}$ cells at $400 \mu \mathrm{g} / \mathrm{mL}$, where cell viability of more than $50 \%$ was observed. EA and $\mathrm{CH}$ extracts of C. excavata, on the other hand, were more toxic to 
$\mathrm{HaCaT}$ cells at 200 and $400 \mu \mathrm{g} / \mathrm{mL}$ (Figure 1A). The $\mathrm{MOH}$ and EA extracts of $C$. excavata were slightly toxic to Vero cells at $400 \mu \mathrm{g} / \mathrm{mL}$ only, while $\mathrm{CH}$ and PT C. excavata extracts were innocuous to these cells at the same dose (Figure 1B). However, proliferation of the $\mathrm{HaCaT}$ and Vero cells increased following exposure to the extracts at low doses.

\section{Gross wound closure}

The gross appearances of wounds at days 5, 10, and 15 post-wound infliction are presented in Figure 2. The groups treated with various concentrations of MECE and intrasite gel showed minimal scar formation when compared with the gum acacia-treated control group, which showed incomplete wound closure. The skin wound areas in MECE-treated rats are presented in Table 1. The gross appearance of wound sites

\section{D5}

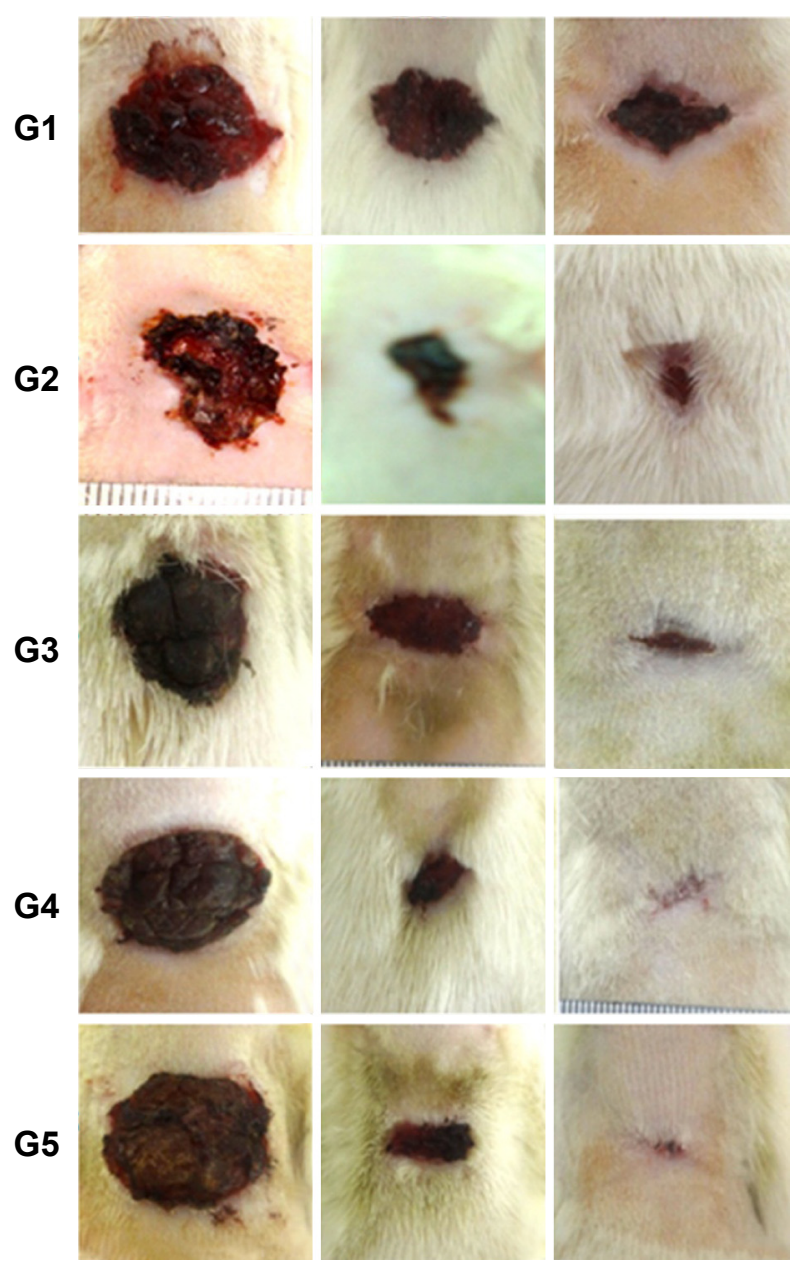

Figure 2 Gross skin lesion showing wound healing.

Notes: (GI) gum acacia-treated group (control), showing incomplete wound healing; (G2) intrasite gel group; (G3) MECE-LD (50 mg/kg) group; (G4) MECE-MD (100 mg/kg) group; and (G5) MECE-HD (200 mg/kg) group.

Abbreviations: D5, day 5; DI0, day 10; DI5, day 15 post-wound infliction; MECE, methanolic extract Clausena excavata; LD, low dose $(50 \mathrm{mg} / \mathrm{mL})$; $M D$, medium dose (100 mg/mL); HD, high dose $(200 \mathrm{mg} / \mathrm{mL})$. was similar among groups at day 5 post-wound infliction. The difference between the negative control group and the MECEtreated group on day 5 post-wounding was not significant.

However, at days 10 and 15, the rate of wound contraction was significantly different $(P=0.0005 ; P<0.0001)$ in the MECE-treated group than in the negative control group. Although the rate of wound contraction appears to be highest on day 15 (Figure 2C-E), there was no significant $(P>0.05)$ difference in the rate of healing among the treatment groups.

\section{Histopathological assessment of wound healing H\&E-stained sections}

The histopathological changes observed in the tissue sections are summarized in Table 2 . There was significantly $(P<0.0001)$ greater epithelialization in the epidermis of the treatment groups than in that of the control group. In general, more inflammatory cells $(P=0.0039)$, degeneration ( $P=0.0011)$, and granulation tissue $(P=0.0320)$ were observed in the skin of the control group than in that of the treatment groups, suggesting enhanced healing response in the MECEtreated groups after wound infliction (Figure 3A).

\section{MT-stained sections}

The changes in Masson trichome-stained skin tissues are presented in Table 3. The color intensity of the stained tissues was significantly $(P<0.05)$ greater in the MECE-HD group than in the other groups. There was significantly $(P=0.0003)$ lesser distribution of fibroblasts in the control group than in the other treatment groups. Collagen maturity was higher $(P=0.0009)$ in the MECE-HD and intrasite groups, while the rates of angiogenesis $(P=0.0121)$ and collagen distribution $(P=0.0041)$ were significantly $(P<0.05)$ higher in the MECE-MD and MECE-HD compared with the other groups (Figure 3B).

\section{VEGF and TGF- $\beta$ I in skin section}

The number of VEGF-positive cells was significantly $(P=0.0002)$ lower in the control and MECE-LD groups than in the MECE-HD, MECE-MD, or intrasite groups (Figure 4). Extracellular matrix deposition as determined by the number of TGF- $\beta 1$-positive cells was significantly $(P<0.0001)$ higher in tissues treated with MECE and intrasite gel than in the control (Figure 5).

\section{Antioxidant enzyme assay}

The SOD activity was significantly higher in the MECE-HD (4.57 $\pm 0.23 ; P=0.007)$, MECE-MD (5.39 $\pm 1.01 ; P=0.001)$, 
Table I Effect of Clausena excavata on percentage of wound healing in experimental rats

\begin{tabular}{llllll}
\hline $\begin{array}{l}\text { Days post-wound } \\
\text { infliction }\end{array}$ & \multicolumn{4}{l}{ Wound healing postsurgery $(\%)$ in different groups } \\
\cline { 2 - 6 } & Control & MECE-LD & MECE-MD & MECE-HD \\
\hline Day 5 & $21.2 \pm 5.1$ & $38.8 \pm 2.6$ & $34.5 \pm 6.7$ & $34.8 \pm 4.5$ & Intrasite \\
Day 10 & $67.2 \pm 4.3^{\mathrm{a}}$ & $86.7 \pm 1.6^{\mathrm{b}}$ & $84.1 \pm 1.5^{\mathrm{b}}$ & $82.9 \pm 2.5^{\mathrm{b}}$ & $20.2 \pm 1.3$ \\
Day 15 & $78.9 \pm 2.5^{\mathrm{a}}$ & $95.7 \pm 0.6^{\mathrm{b}}$ & $97.4 \pm 0.9^{\mathrm{b}}$ & $98.8 \pm 0.4^{\mathrm{b}}$ & $78.7 \pm 1.2^{\mathrm{b}}$ \\
\hline
\end{tabular}

Notes: All values were expressed as mean \pm SE (standard error of mean). a,bMean with different superscripts within the same row are significantly different from each other $(P<0.05)$, while those with the same superscripts within a row are not significantly different $(P<0.05)$.

Abbreviations: MECE, methanol extract Clausena excavata; LD, low dose (50 mg/mL); MD, medium dose (I00 mg/mL); HD, high dose (200 mg/mL).

and intrasite gel groups $(4.91 \pm 0.89 ; P=0.003)$ than that in the control group (1.83 \pm 0.27$)$. There was no statistical difference between the treated groups (Figure 6A). The CAT activity was significantly higher in the MECE-HD (28.55 \pm 4.1 ; $P=0.002)$ and intrasite gel groups $(26.90 \pm 1.79 ; P=0.008)$ than that in the control group (17.82 \pm 1.07 ) (Figure 6B). In addition, there was an increase in the MECE-MD (23.77 \pm 1.40$)$ and MECE-LD (20.91 \pm 0.90$)$ groups but it was not significant. The GPx activity was significantly $(P=<0.001)$ higher in the intrasite and MECE-MD groups (32.9 \pm 1.87 , $29.33 \pm 1.52$, respectively) than in the control (16.4 \pm 0.35$)$, MECE-HD, (23.0 \pm 2.5$)$ or MECE-LD (21.8 \pm 2.02$)$ groups (Figure 6C). The LPO activity was significantly higher in the control group $(9.12 \pm 1.76)$ than in the intrasite $(2.81 \pm 0.94$; $P=0.001)$, MECE-HD (4.17 $\pm 1.10 ; P=0.006)$, MECE-MD (4.85 $\pm 0.75 ; P=0.013)$, or MECE-LD $(4.09 \pm 0.76 ; P=0.001)$ groups (Figure 6D). These results collectively show that wounds dressed with MECE may protect it from LPO during the healing process and thus contribute remarkably to acceleration of wound healing.

\section{Discussion}

In the past couple of decades, ethnopharmacology has become a focus area for researchers in the search for natural materials with potent antioxidant and healing properties. ${ }^{6}$ Among the properties of pure natural compounds and extracts investigated was wound healing, and the results were remarkable. ${ }^{16-20}$ In this study, the C. excavata MECE extract was examined for its wound healing properties. C. excavata contains coumarins, flavonoids, and glycosides with a wide array of biological properties. ${ }^{1,14,21,22}$

Various solvents with increasing polarity have been frequently used for the extraction of polyphenols and flavonoids from plants, and since the biological activity of extracts has a strong relationship with the solvents employed on the basis of their polarities, we used different extracts from C. excavata leaves to determine their effect on in vitro cell lines. ${ }^{23,24} \mathrm{We}$ observed that the $\mathrm{MOH}$ extract had cell viability of $71 \%$ and $47 \%$ at $400 \mu \mathrm{g} / \mathrm{mL}$ to the $\mathrm{HaCaT}$ and Vero cells, respectively. It was also observed that at low doses, the MECE and PT extracts of $C$. excavata enhanced the proliferation of these cells. The MECE contains quercetin and myricetin that has been shown to enhance the growth of the normal human skin fibroblast (FS5) cell line by conferring protection on these cells against hydrogen peroxide-induced damage. ${ }^{14,17}$

However, the nonpolar solvent (EA and $\mathrm{CH}$ ) extracts showed a significant reduction in the percentage of cell viability in the $\mathrm{HaCaT}$ cells with $19 \%$ and $27 \%$ at $400 \mu \mathrm{g} / \mathrm{mL}$, respectively. This may indicate that nonpolar active principles are responsible for the antiproliferative activity of this plant as previously reported in other plants. ${ }^{25,26}$ High

Table 2 Histopathological evaluation of the epidermis and dermis of H\&E-stained skin sections of Clausena excavata methanol extracttreated rats

\begin{tabular}{|c|c|c|c|c|c|}
\hline \multirow[t]{2}{*}{ Parameters } & \multicolumn{5}{|c|}{ Lesion score (unit) } \\
\hline & Control & MECE-LD & MECE-MD & MECE-HD & Intrasite \\
\hline \multicolumn{6}{|l|}{ Epidermis } \\
\hline Epithelialization & $0.5 \pm 0.2^{\mathrm{a}}$ & $4.0 \pm 0.0^{b}$ & $4.0 \pm 0.0^{\mathrm{b}}$ & $4.0 \pm 0.0^{b}$ & $4.0 \pm 0.0^{\mathrm{b}}$ \\
\hline Inflammatory cells & $2.5 \pm 0.6^{\mathrm{a}}$ & $0.3 \pm 0.2^{b, c}$ & $1.7 \pm 0.2^{\mathrm{a}, \mathrm{c}}$ & $0.5 \pm 0.2^{b, c}$ & $1.5 \pm 0.2^{\mathrm{a}, \mathrm{c}}$ \\
\hline Degeneration & $2.3^{\mathrm{a}} \pm 0.5$ & $0.5^{\mathrm{b}} \pm 0.2$ & $0.5^{\mathrm{b}} \pm 0.2$ & $0.7^{b} \pm 0.2$ & $2.3^{\mathrm{a}} \pm 0.2$ \\
\hline \multicolumn{6}{|l|}{ Dermis } \\
\hline Granulation tissue & $2.7 \pm 0.3^{\mathrm{a}}$ & $1.3 \pm 0.2^{\mathrm{b}}$ & $1.8 \pm 0.3^{\mathrm{a}, \mathrm{b}}$ & $1.5 \pm 0.3^{b}$ & $1.8 \pm 0.2^{\mathrm{a}, \mathrm{b}}$ \\
\hline Inflammatory cells & $2.5 \pm 0.2^{\mathrm{a}}$ & $1.5 \pm 0.2^{b, c}$ & $1.2 \pm 0.2^{b}$ & $1.0 \pm 0.0^{\mathrm{b}}$ & $2.1 \pm 0.2^{\mathrm{a}, \mathrm{c}}$ \\
\hline
\end{tabular}

Notes: All values were expressed as mean \pm standard error mean; ${ }^{a-c}$ Mean with different superscripts within the same row are significantly different from each other $(P>0.05)$, while those with the same superscripts within a row are not significantly different $(P>0.05)$; lesions were scored based on a five-point scale: $0-$ normal, $0 \%$; I occasional evidence, $25 \%$; 2 - light scattering, 30\%-50\%; 3 - abundant evidence, 55\%-75\%; and 4 - confluent cell, $80 \%-100 \%$.

Abbreviations: MECE, methanol extract Clausena excavata; LD, low dose (50 mg/mL); MD, medium dose (I00 mg/mL); HD, high dose (200 mg/mL). 

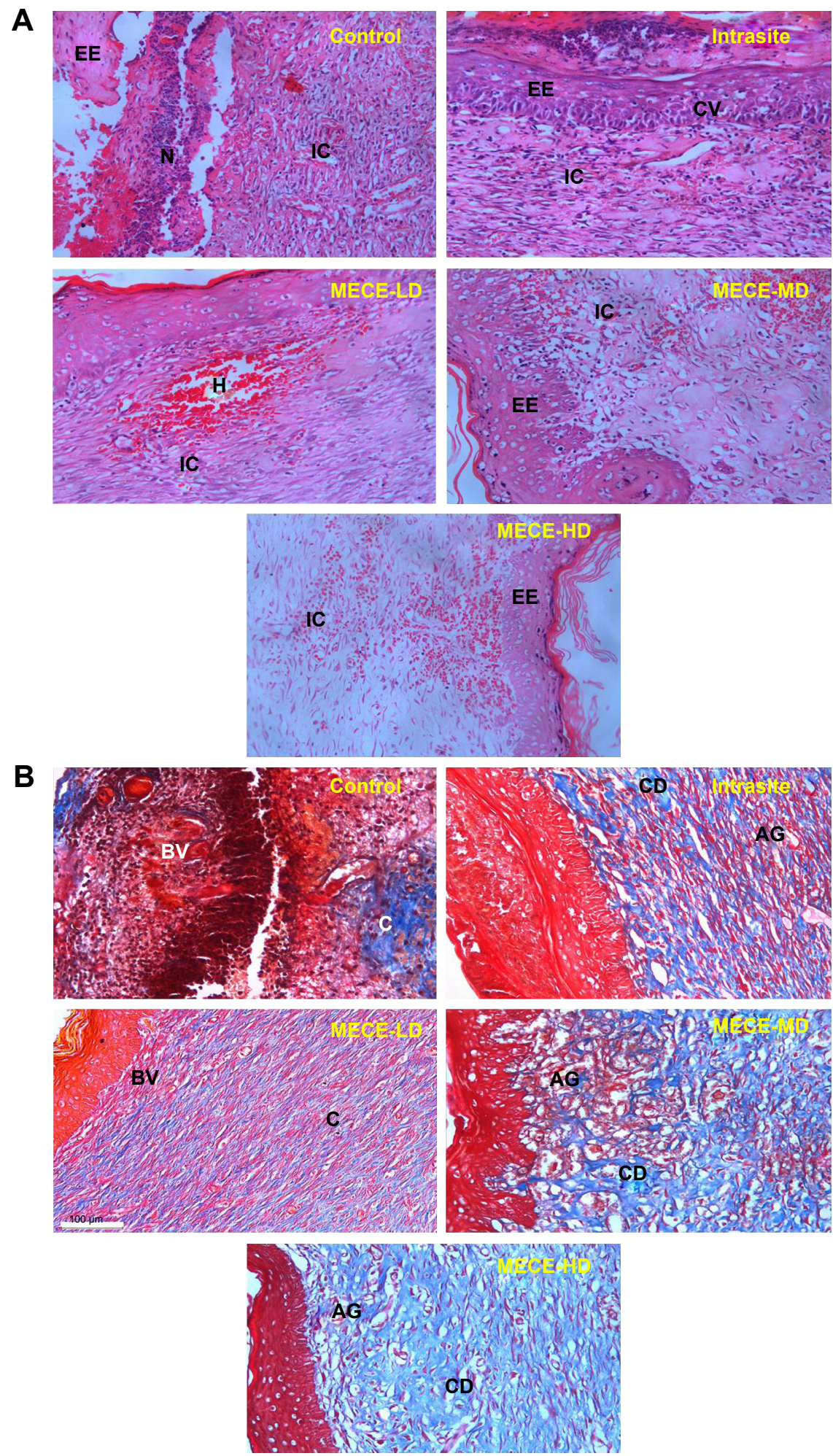

Figure 3 Histopathological evaluation of skin sections.

Notes: (A) Skin sections showing (Control) incomplete epidermal epithelialization (EE) with necrosis $(\mathrm{N})$ and abundant inflammatory cell response (IC) in the dermis; (Intrasite) complete EE with cellular vacuolation (CV) and light scattering of inflammatory cells (IC) in the dermis; (MECE-LD) incomplete EE and a focus of hemorrhage $(\mathrm{H})$ in the dermis; (MECE-MD) complete EE with occasional evidence of IC in the dermis; and (MECE-HD) complete EE and occasional evidence of IC in the dermis (H\&E, 200x). (B) Skin sections showing (Control) occasional evidence to light scattering of collagen (C) with occasional evidence of blood vessels (BV) in the dermis; (Intrasite) light scattering to abundant evidence of angiogenesis (AG) and collagen distribution (CD), but moderate collagen color intensity; (MECE-LD) occasional evidence to light scattering of collagen (C) with abundant evidence of blood vessels (BV) in the dermis; (MECE-MD) abundant evidence of angiogenesis (AG) and collagen distribution (CD) with moderate collagen color intensity; (MECE-HD) abundant evidence of angiogenesis (AG), confluent distribution of collagen (CD) with moderate collagen color intensity. (Masson Trichome, 200x).

Abbreviations: MECE, methanolic extract Clausena excavata; LD, low dose (50 mg/mL); MD, medium dose (100 mg/mL); HD, high dose $(200 \mathrm{mg} / \mathrm{mL})$. 
Table 3 Evaluation of connective tissue and vascular proliferation in Masson's trichrome-stained skin sections of Clausena excavata methanol extract-treated rats

\begin{tabular}{llllll}
\hline Parameter & \multicolumn{2}{l}{ Lesion score (unit) } & & MECE-HD & Intrasite \\
\cline { 2 - 6 } & Control & MECE-LD & MECE-MD & $2.7 \pm 0.2^{\mathrm{c}}$ & $1.2 \pm 0.2^{\mathrm{b}}$ \\
\hline Intensity of coloration & $1.6 \pm 0.2^{\mathrm{a}, \mathrm{b}}$ & $1.5 \pm 0.2^{\mathrm{a}, \mathrm{b}}$ & $2.3 \pm 0.2^{\mathrm{a}, \mathrm{c}}$ & $3.5 \pm 0.2^{\mathrm{b}}$ & $2.8 \pm 0.2^{\mathrm{b}}$ \\
Fibroblast distribution & $1.5 \pm 0.2^{\mathrm{a}}$ & $2.7 \pm 0.2^{\mathrm{b}}$ & $3.3 \pm 0.2^{\mathrm{b}}$ & $3.3 \pm 0.4^{\mathrm{c}}$ & $2.5 \pm 0.2^{\mathrm{b}, \mathrm{c}}$ \\
Collagen maturity & $1.3 \pm 0.2^{\mathrm{a}}$ & $1.5 \pm 0.2^{\mathrm{a}}$ & $2.0 \pm 0.0^{\mathrm{a}, \mathrm{b}}$ & $3.1 \pm 0.2^{\mathrm{b}, \mathrm{c}}$ & $2.7 \pm 0.2^{\mathrm{a}}$ \\
Angiogenesis rate & $2.0 \pm 0.4^{\mathrm{a}}$ & $2.3^{\mathrm{a}} \pm 0.2^{\mathrm{a}, \mathrm{b}}$ & $3.5 \pm 0.2^{\mathrm{c}}$ & $4.0 \pm 0.0^{\mathrm{b}, \mathrm{c}}$ & $2.8 \pm 0.2^{\mathrm{a}, \mathrm{c}}$ \\
Collagen distribution & $2.1 \pm 0.6^{\mathrm{a}}$ & $2.2 \pm 0.2^{\mathrm{a}}$ & $3.7 \pm 0.2^{\mathrm{b}, \mathrm{c}}$ & &
\end{tabular}

Notes: All values were expressed as mean \pm standard error of mean. ${ }^{a-c}$ Mean with different superscripts within the same row are significantly different from each other $(P<0.05)$, while those with the same superscripts within a row are not significantly different $(P<0.05)$; fibroblast distribution, collagen distribution, and angiogenesis rate were scored on a five-point scale: 0 - normal, $0 \%$; I - occasional evidence, $25 \%$; 2 - light scattering, 30\%-50\%; 3 - abundant evidence, 55\%-75\%; 4 - confluent cell, $80 \%-100 \%$. Collagen intensity was assessed based on subjective evaluation of blue color intensities as follows: no coloration (0), low (1), dull (2), moderate (3), and bright colorations (4). Collagen maturity was assessed based on level of maturation of collagen fibers: no collagen (0), semithin fibers (I), thin fibers (2), semithick fibers (3), thick fibers (4).

Abbreviations: MECE, methanol extract Clausena excavata; LD, low dose (50 mg/mL); MD, medium dose (I00 mg/mL); HD, high dose (200 mg/mL).

flavonoids content has been reported to be responsible for antiproliferative activity in cranberry. ${ }^{27}$ Our previous study on the phytochemical screening of this plant showed the presence of high flavonoids in the $\mathrm{CH}$ extracts, which is responsible for the low proliferation observed here. ${ }^{14}$ The percentage cell viability observed in Vero cells was similar to that of $\mathrm{HaCaT}$ cells, but Vero cells were more resistant (51\% and $78 \%$ at $400 \mu \mathrm{g} / \mathrm{mL}$ ) than $\mathrm{HaCaT}$ cells following exposure to EA and $\mathrm{CH}$. This selectivity could be due to the sensitivity of the cell line to the active compounds in the extract. ${ }^{28}$

The wound healing properties of MECE was determined in a rat model by application of the extract to skininflicted wounds. The extract increased wound contraction in all the treated groups by days 10 and 15 . Histopathologically, the treated skin showed decreased inflammatory response, degeneration, granulation tissue, angiogenesis rate, collagen intensity, maturation, and distribution in the MECE-HD group. The findings are similar to that of previous studies that used different compounds and/or plants such as 3-(2-chlorophenyl)-1-phenyl-propenomein, ethanol extract of Bacopa monniera, Elaeagus angustofolia, Centaurea sadleriana janka, Blechnum orientale Linn, and Camellia sinensis. ${ }^{16-20}$ Compounds containing polyphenols have immense health benefits in view of their antioxidant, anti-inflammatory, and antimicrobial effects. These effects are responsible for the acceleration of wound healing that is facilitated by rapid wound closure and increased rate of epidermal regeneration, ${ }^{19,29}$ and these effects are attributed to the high phenolic content of MECE. ${ }^{14,30}$

VEGF mediates angiogenesis and granulation tissue formation during wound healing. This cytokine, expressed in leukocytes stimulates reactive oxygen species (ROS) production. ${ }^{9}$ In fact, increased VEGF expression has been reported to be associated with accelerated wound healing in model animals, while decreased expression occurred in poor wound healing. ${ }^{11,31}$ We observed that MECE-MD and MECE-HD treatments increased the number of VEGFpositive cells in the wound tissue sections, which is suggested to be associated with increase in the growth factor expression. However, the pathway by which $C$. excavata extract induced this effect is unclear. It is possible that the anti-inflammatory properties of $C$. excavata extract are attributable to fucranocoumarins such as angelicin, which has been used as a medicinal agent in the treatment of psoriasis. This compound regulates inflammation via inhibition of the MAPK/NF- $\mathrm{KB}$ pathways. ${ }^{32}$ Our findings also showed that MECE-MD and MECE-HD treatments increased TGF- $\beta 1$ expression; a cytokine enhances wound contraction, deposition of extracellular matrix, and collagen formation in the healing wounds. ${ }^{8}$ This suggests that one of the effects of MECE is to increase deposition of ECM in the skin wounds, facilitating healing.

In our previous study, we showed that MECE possesses high radical scavenging activities. ${ }^{14}$ However, it was uncertain whether this activity was similar in vivo and whether it would enhance wound healing. Antioxidants enhance the healing process by reducing the damage to tissue and cell structures including membrane lipids, proteins, enzymes, and nucleic acids caused by the production of ROS during the process of tissue injury. The antioxidant enzymes (SOD, $\mathrm{CAT}$, and GPx) are known to overcome radicals and thus prevent the damage to cells caused by them. ${ }^{25,30}$ This was shown in a previous study using Plagiochasma appendiculatum Lehm, where enhanced wound healing rate was attributed to decreased activity of LPO and increased activities of SOD and CAT. ${ }^{33}$ Similarly, we observed increased SOD and CAT, 

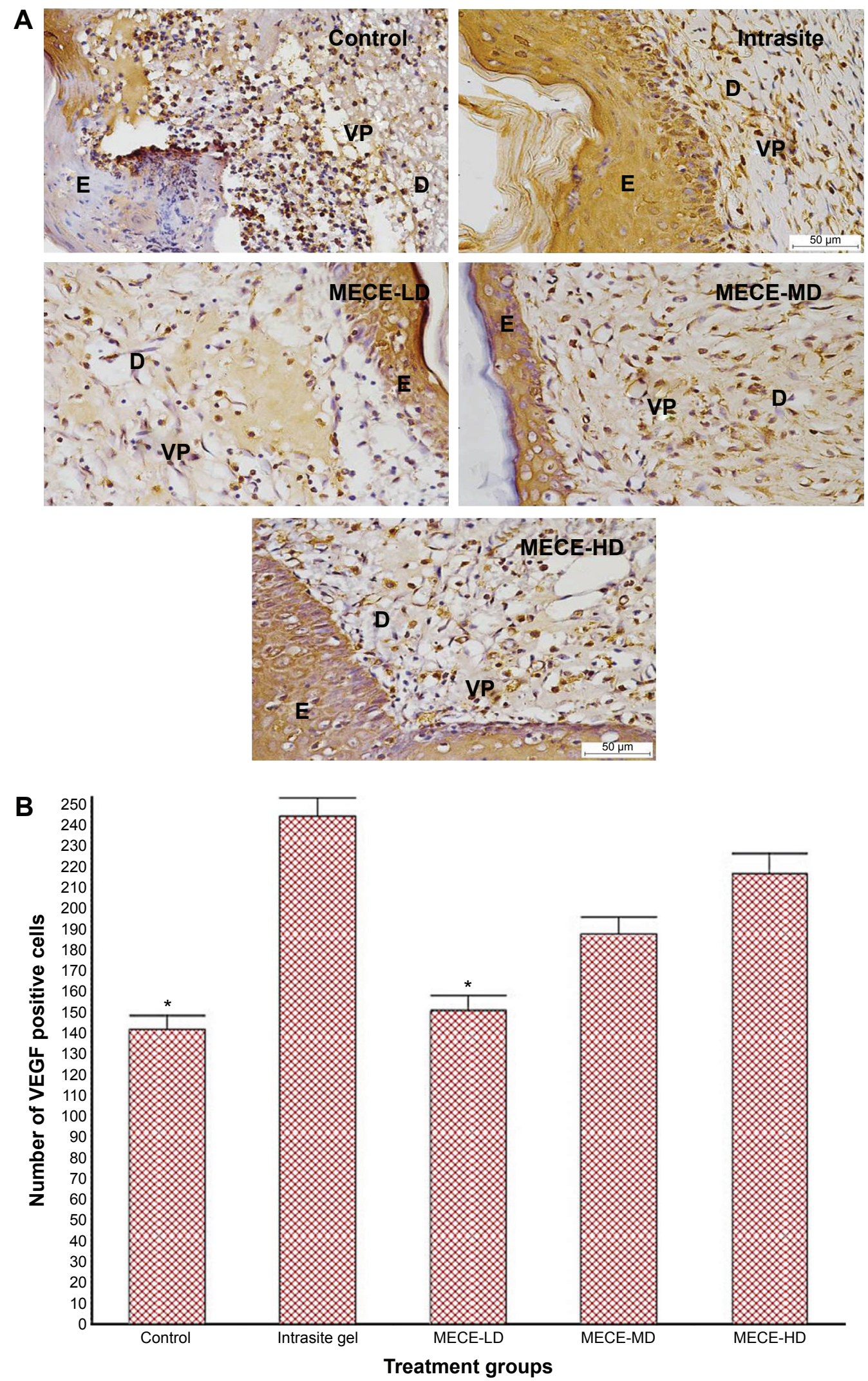

Figure 4 Quantitative estimation of VEGF reaction.

Notes: (A) Skin sections showing epidermis (E) and distribution of light to dark brown VEGF-positive cells (VP) in the dermis (D) in the various experimental groups: (Control), (MECE-LD), (MECE-MD), (MECE-HD), and (Intrasite). (Immunoperoxidase, 400×). (B) Bar graph showing distribution of VEGF-positive cells in the Control, Intrasite, and MECE-treated rat skin wound. *Indicates significance differences at $P<0.05$.

Abbreviations: MECE, methanolic extract Clausena excavata; LD, low dose (50 mg/mL); MD, medium dose (I00 mg/mL); HD, high dose (200 mg/mL). 
A
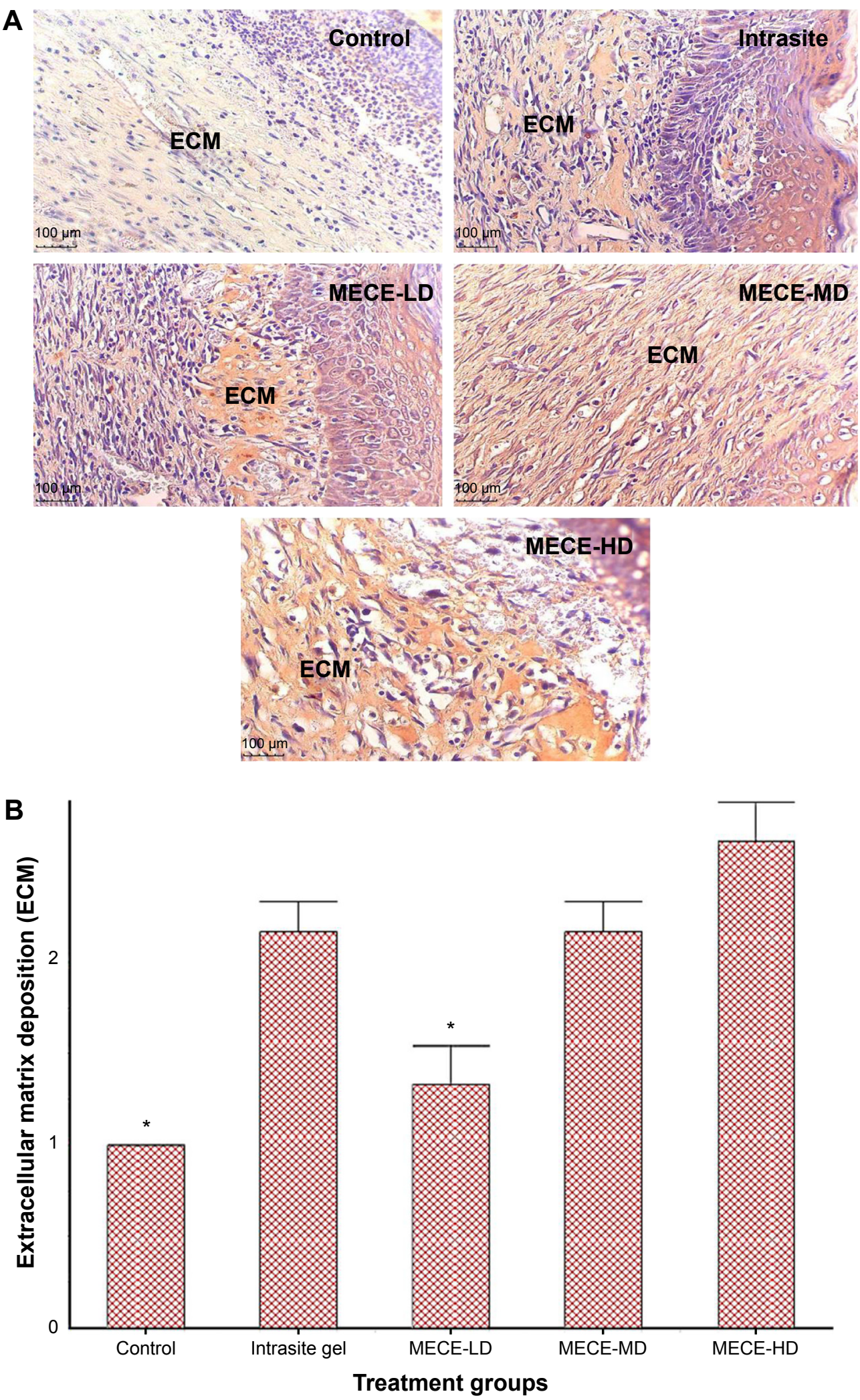

Figure 5 Evaluation of TGF $\beta$ I distribution.

Notes: (A) Skin sections stained for TGF- $\beta$ I showing (Control) little deposition of extracellular matrix (ECM), (Intrasite) moderate ECM deposition, (MECE-LD) little to moderate ECM deposition, (MECE-MD) moderate ECM deposition, (MECE-HD) confluent ECM deposition. (Immunoperoxidase, 200x). (B) Bar graph showing distribution of extracellular matrix (ECM) in TGF- $\beta$ I-stained skin sections of control, intrasite gel, and MECE-treated rat skin wound. *Indicates significance differences at $P<0.05$. The extracellular matrix distribution (ECM) was evaluated by using a four-point scale; 0 (no ECM); 0\%, I (little ECM); $30 \%, 2$ (moderate ECM); $65 \%$ and 3 (confluent ECM); $70 \%-100 \%$, modified as previously described by Atiba et al. ${ }^{9}$

Abbreviations: MECE, Methanolic extract Clausena excavata; LD, low dose $(50 \mathrm{mg} / \mathrm{mL})$; MD, medium dose (I00 mg/mL); HD, high dose (200 mg/mL). 
A
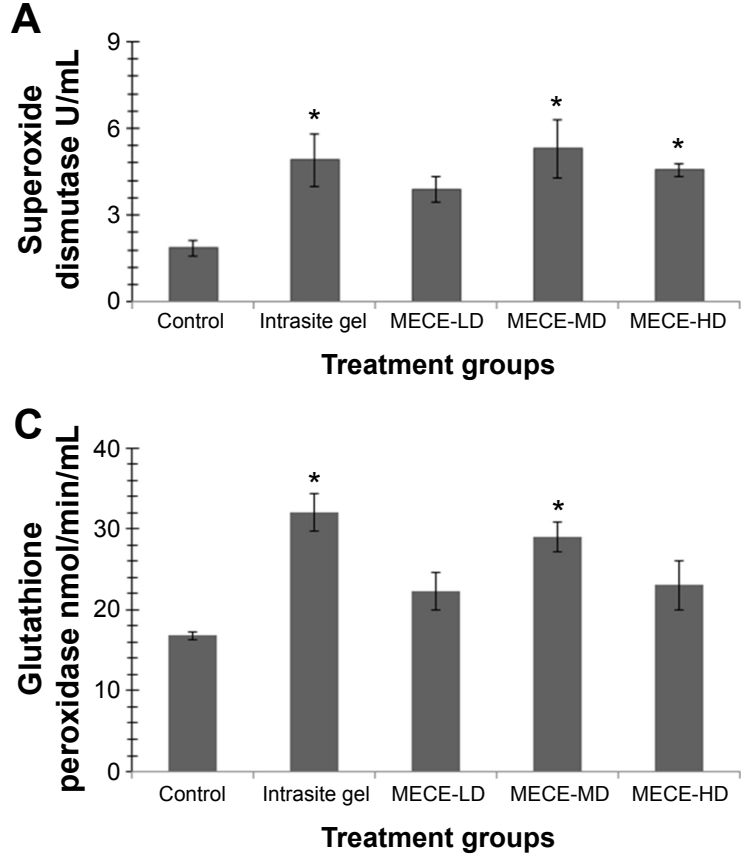

B

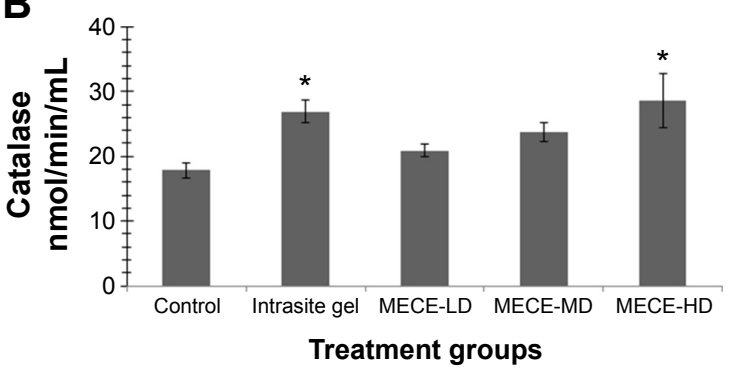

D

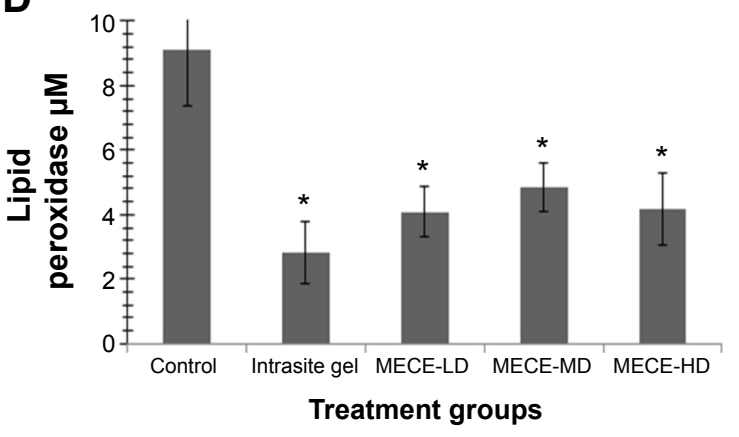

Figure 6 Bar graphs showing activities of superoxide dismutase (A), catalase (B) glutathione peroxidase (C), and lipid peroxidase (D) in control, intrasite gel, and MECEtreated skin wound in rats.

Notes: Values are depicted as Mean \pm SE, *significance $(P<0.05)$ difference compared with control.

Abbreviations: MECE, Methanolic extract Clausena excavata; LD, low dose (50 mg/mL); MD, medium dose (100 mg/mL); HD, high dose (200 mg/mL).

and decreased LPO activities in the MECE-HD group. These enzymes are very important mediators of oxidative stress as they catalyze the breakdown of ROS such as superoxide and hydrogen ions. ${ }^{33}$ The inhibition of ROS production and LPO promotes fibroblast proliferation, neovascularization, and the healing process of wounds. ${ }^{16}$ Earlier reports have shown that several compounds isolated from the roots of $C$. excavata exhibited profound antimicrobial properties. ${ }^{34}$ Thus, the healing properties exhibited by MECE is attributable to its antioxidant and antimicrobial activities, which in turn result from high phenolic content. ${ }^{14}$

The results of this study showed that topical applications of MECE enhanced wound healing by improving different components of wound repair, including reduced inflammation, angiogenesis, increased collagen synthesis, and enhanced wound contraction, as well as decreased activities of lipid peroxidase and increased SOD, CAT, and GPx activities. VEGF and TGF- $\beta 1$ expression in the MECEtreated group was dramatically increased and was higher than in the control group. However, an investigation of the major active compounds in MECE is still required to fully understand its mechanism of wound healing.

\section{Acknowledgment}

This study was financially supported by the University of Malaya PPP Grant number PG0592013A.

\section{Author contributions}

All authors contributed toward data analysis, drafting and revising the paper and agree to be accountable for all aspects of the work.

\section{Disclosure}

The authors report no conflict of interest in this work.

\section{References}

1. Rahman MT, Alimuzzaman M, Shilpi JA, Hossain MF. Antinociceptive activity of Clausena excavata leaves. Fitoterapia. 2002;73(7): 701-703.

2. Manosroi A, Saraphanchotiwitthaya A, Manosroi J. Immunomodulatory activities of Clausena excavata Burm. $f$. wood extracts. J Ethnopharmacol. 2003;89(1):155-160.

3. Sharif NWM, Mustahil NA, Mohd Noor NS, et al. Cytotoxic constituents of Clausena excavata. Afr J Biotechnol. 2011;10(72):16337-16341.

4. Kumar R, Saha A, Saha DA. New antifungal coumarin from Clausena excavata. Fitoterapia. 2012;83(1):230-233.

5. Guntupalli C, Kumar GS, Kumar AS, Tubati T. Evaluation of antioxidant activity of the methanolic leaf extract of Clausena excavata Burm. f. (Rutaceae) using the lipid peroxidation model. Pharmacogn $J$ 2012;4(34):22-25.

6. Geethalakshmi R, Sakravarthi C, Kritika T, Arul Kirubakaran M, Sarada DV. Evaluation of antioxidant and wound healing potentials of Sphaeranthus amaranthoides Burm.f. Biomed Res Int. 2013;2013. 607109.

7. Ilango K, Chitra V. Wound healing and anti-oxidant activities of the fruit pulp of Limonia Acidissima Linn (Rutaceae) in rats. Trop J Pharm Res. 2010;9(3):223-230.

8. Ram M, Singh V, Kumar D, et al. Antioxidant potential of bilirubinaccelerated wound healing in streptozotocin-induced diabetic rats Schmiedeberg's Arch Pharmacol. 2014;387(10):955-961. 
9. Atiba A, Ueno H, Uzuka Y. The effect of aloe vera oral administration on cutaneous wound healing in type 2 diabetic rats. J Vet Med Sci. 2011; 73(5):583-589.

10. Majewska I, Gendaszewska-Darmach E. Proangiogenic activity of plant extracts in accelerating wound healing - a new face of old phytomedicines. Acta Biochim Pol. 2011;58(4):449-460.

11. Manoj GS, Murugan K. Wound healing activity of methanolic and aqueous extracts of Plagiochila beddomei Steph. thallus in rat model. Indian J Exp Biol. 2012;50(8):551-558.

12. Nagappan T, Segaran TC, Wahid ME, Ramasamy P, Vairappan CS. Efficacy of carbazole alkaloids, essential oil and extract of Murraya koenigii in enhancing subcutaneous wound healing in rats. Molecules. 2012;17(12):14449-14463.

13. Venugopala KN, Rashmi V, Odhav B. Review on natural coumarin lead compounds for their pharmacological activity. Biomed Res Int. 2013; 963248.

14. Albaayit SF, Abba Y, Abdullah R, Abdullah N. Evaluation of antioxidant activity and acute toxicity of Clausena excavata leaves extract. Evid Based Complement Alternat Med. 2014;2014:975450.

15. Riss TL, Moravec RA, Niles AL, et al. Cell viability assays. In: Sittampalam GS, Coussens NP, Nelson H, et al, editors. Assay Guidance Manual [Internet]. Bethesda, MD: Eli Lilly \& Company and the National Center for Advancing Translational Sciences; 2013. Available from: http://www.ncbi.nlm.nih.gov/books/NBK144065/. Accessed May 19, 2015.

16. Murthy S, Gautam MK, Goel S, Purohit V, Sharma H, Goel RK. Evaluation of in vivo wound healing activity of Bacopa monniera on different wound model in rats. Biomed Res Int. 2013;2013:972028.

17. Adetutu A. Evaluation of Wound Healing Activity of Selected Nigerian Plants. [dissertation]. London: University of East London; 2009.

18. Csupor D, Blazsó G, Balogh Á, Hohmann J. The traditional Hungarian medicinal plant Centaure asadleriana Janka accelerates wound healing in rats. J Ethnopharmacol. 2010;127(1):193-195.

19. Lai HY, Lim YY, Kim KH. Potential dermal wound healing agent in Blechnum orientale Linn. BMC Complement Altern Med. 2011; 11(1):62.

20. Natanzi MM, Pasalar P, Kamalinejad M, et al. Effect of aqueous extract of Elaeagnus angustifolia fruit on experimental cutaneous wound healing in rats. Acta Med Iran. 2012;50(9):589-596.

21. Hajiaghaalipour F, Kanthimathi MS, Abdullah MA, Sanusi J. The effect of Camellia sinensis on wound healing potential in an animal model. Evid Based Complement Alternat Med. 2013;2013:386734.
22. Ito $\mathrm{C}$, Itoigawa $\mathrm{M}, \mathrm{Katsuno} \mathrm{S}$, et al. Chemical constituents of Clausena excavata: isolation and structure elucidation of novel furanonecoumarins with inhibitory effects for tumor-promotion. J Nat Prod. 2000;63(9):1218-1224.

23. Yang J, Chen C, Zhao S, Ge F, Liu D. The inhibitory effect of different solvents extracts from walnut shell (Juglans regia L.) on pancreatic lipase and adipogenesis of 3T3-L1 preadipocytes. J Food Nutr Res. 2014; 2(10):664-670

24. Fernández-Agulló A, Pereira E, Freire MS, et al. Influence of solvent on the antioxidant and antimicrobial properties of walnut (Juglans regia L.) green husk extracts. Ind Crop Prod. 2013;42:126-132.

25. Priya S, Noor A, Satheeshkumar PK. Antioxidant and anti-proliferative activity of different solvent extracts of Casuarina equisetifolia needles. Phytomedicine. 2012;4(1):99-107.

26. Talib WH, Mahasneh AM. Antiproliferative activity of plant extracts used against cancer in traditional medicine. Sci Pharm. 2010;78(1):33.

27. Ferguson P, Kurowska E, Freeman D, Chambers A, Koropatnick D. A flavonoid fraction from cranberry extract inhibits proliferation of human tumor cell line. J Nutr. 2004;134(6):1529-1535.

28. Kirana C, Record I, McIntosh G, Jones G. Screening for antitumor activity of 11 species of Indonesian Zingiberaceae using human MCF-7 and HT-29 cancer cells. Pharm Biol. 2003;41(4):271-276.

29. Xin ZQ, Lu JJ, Ke CQ, Hu CX, Lin LP, Ye Y. Constituents from Clausena excavata. Chem Pharm Bull. 2008;56(6):827-830.

30. Sakong P, Khampitak T, Cha'on U, et al. Antioxidant activity and bioactive phytochemical contents of traditional medicinal plants in Northeast Thailand. J Med Plants Res. 2011;5(31):6822-6831.

31. Pessoa WS, Estevão LRDM, Simões RS, et al. Effects of angico extract (Anadenanthera colubrina var. cebil) in cutaneous wound healing in rats. Acta Cir Bras. 2012;27(10):655-670.

32. Liu F, Sun GQ, Gao HY, et al. Angelicin regulates LPS induced inflammation via inhibiting MAPK/NF-B pathways. J Surg Res. 2013; 185(1):300-309.

33. Singh M, Govindarajan R, Nath V, Rawat AK, Mehrotra S. Antimicrobial, wound healing and antioxidant activity of Plagiochasma appendiculatum Lehm. et Lind. J Ethnopharmacol. 2006;107(1):67-72.

34. Wu TS, Furukawa H. Biological and phytochemical investigations of Clausena excavata. J Nat Prod. 1982;45(6):718-720.
Drug Design, Development and Therapy

\section{Publish your work in this journal}

Drug Design, Development and Therapy is an international, peerreviewed open-access journal that spans the spectrum of drug design and development through to clinical applications. Clinical outcomes, patient safety, and programs for the development and effective, safe, and sustained use of medicines are a feature of the journal, which

\section{Dovepress}

has also been accepted for indexing on PubMed Central. The manuscript management system is completely online and includes a very quick and fair peer-review system, which is all easy to use. Visit http://www.dovepress.com/testimonials.php to read real quotes from published authors. 